First Peoples Child \& Family Review

An Interdisciplinary Journal Honouring the Voices, Perspectives, and Knowledges of

First Peoples through Research, Critical Analyses, Stories, Standpoints and Media

Reviews

\title{
Editorial: Summarizing Evidence Based Research and Knowledge Translation; Increasing Graduation Rates; Strengthening Neighbourhoods and Increasing Social Inclusion; Moral Courage in Child Welfare; and Interracial Adoption
}

\section{Marlyn Bennett}

Volume 6, Number 2, 2011

URI: https://id.erudit.org/iderudit/1068871ar

DOI: https://doi.org/10.7202/1068871ar

See table of contents

Publisher(s)

First Nations Child and Family Caring Society of Canada

ISSN

1708-489X (print)

2293-6610 (digital)

Explore this journal

Cite this document

Bennett, M. (2011). Editorial: Summarizing Evidence Based Research and Knowledge Translation; Increasing Graduation Rates; Strengthening

Neighbourhoods and Increasing Social Inclusion; Moral Courage in Child

Welfare; and Interracial Adoption. First Peoples Child \& Family Review, 6(2),

4-6. https://doi.org/10.7202/1068871ar 


\title{
First Peoples Child \& Family Review
}

An Interdisciplinary Journal Honoring the Voices, Perspectives and Knowledges of First

Peoples through Research, Critical Analyses, Stories, Standpoints and Media Reviews

Volume 6, Number 2, 2011, p.4

\section{Editorial: Summarizing Evidence Based Research and Knowledge Translation; Increasing Graduation Rates; Strengthening Neighbourhoods and Increasing Social Inclusion; Moral Courage in Child Welfare; and Interracial Adoption}

\author{
Marlyn Bennett
}

This issue of the First People Child and Family Review journal (Volume 6, Number 2, 2011) is comprised of four articles and a book review. The first article deals with knowledge translation and the utilization of evidence-based research portal used by agencies in Ontario that provide services to Aboriginal youth in care. The second article speaks to the creation of an education program in Calgary that was developed specifically to increase graduation rates among Aboriginal students. The third article highlights another initiative in Calgary regarding the Family and Community Support Services Social Sustainability Framework in strengthening neighbourhoods and increasing social inclusion among urban First Peoples. Moral courage is the focus of the final article in this volume and the importance of this value in standing up for what is equitably right when it comes to Aboriginal children and families engaged with the child welfare system. We end this issue with the first of many book reviews that will appear in future issues of the journal. The book review in this issue looks at international and interracial adoption and migration in the Americas. Each of these is briefly summarized below.

Non-Aboriginal child protective service workers' utilization of the Maltreatment and Adolescent Pathway Knowledge Translation (MAP-KT) Portal: A report on the utilization statistics and utilization gaps of Aboriginal best-practice material (pp. 7-13), by Eman Leung, Christine
Wekerle, Randy Weachter, Julian Egelstaff and Marlyn Bennett is an evaluation based article on the utilization of Aboriginal data useful for knowledge translation by agency caseworkers responsible for the care of Aboriginal youth. The MAP-KT portal is a web-based tool that was created specifically to share knowledge that might be useful to Ontario agencies needing evidencebased knowledge to assist with practice decision and issues when working with families. Leung and colleagues describe specifically the way non-Aboriginal caseworkers used the Aboriginal child welfare research evidence to inform their decision making for Aboriginal youth in care. The researchers hypothesized that since $10 \%$ of youth in the MAP-KT database were Aboriginal then at least $10 \%$ of the traffic to the portal would be for the purposes of accessing Aboriginal material to inform practice. This hypothesis turned out not to be the case. The researchers note this finding represents an underutilization potential needed to bridge the gap between knowledge and action in the practice of caring for Aboriginal children and youth involved in the child welfare system.

The MacPhail Family Aboriginal Pride Program of Calgary (pp. 14-19), written by Joanne Pinnow and Shane Gauthier is about a successful pilot project created specifically to increase the graduation rates among Aboriginal youth in the City of Calgary. The McPhail Family Aboriginal Pride Program theorized that low graduation rates were as a result of social exclusion. 
As the school curriculum in the past did not emphasize Aboriginal culture and history there was a loss of interest in school by Aboriginal students who felt demoralized. The program was created to be developmentally appropriate and pays attention to different age groups. It includes a socio-culturally relevant philosophy that is founded on the application of Aboriginal content in the curriculum, creates greater awareness of Aboriginal culture and history and it includes culturally relevant activities that acknowledge Aboriginal beliefs and practices. It targets children in youth enrolled in kindergarten to grade twelve. The program offers academic support, empowerment and cultural teachings within an inclusive respectful environment. The program reinforces positive cultural identity that is important for creating a sense of belonging and to help students feel valued, connected and engaged within the school community. This tailored approach has seen much success. The authors report that students feel more socially accepted and more importantly, the program demonstrates that graduation has become possible for many Aboriginal students who have benefited from this approach to education.

The following articles focuses on another successful initiative underway in the City of Calgary. Shane Gauthier, Sharon Goulet and Katie Black co-wrote Calgary's Family and Community Support Services' Social Sustainability Framework and Urban Aboriginal Peoples (pp. 20-34). The purpose of the paper is to introduce readers to the Family and Community Support Services' Social Sustainability Framework and provides examples of two programs where funding has helped strengthen neighborhoods and increases social inclusion among vulnerable populations like First Peoples - two principles emphasized as important within the framework. Social exclusion (where a person feels a lack of belonging and recognition) and deprivation are part of the underlying factors in the overrepresentation of Aboriginal people in various systems (i.e. child welfare, criminal justice system). Strengthening neighborhoods and increasing social inclusion are priority-funding areas chosen because concentrated poverty and social isolation are very serious problems as they have far reaching consequences for individual, families and the greater community of Calgary. Also it was recognized that concentrated poverty and social isolation are on the rise in Calgary but are easily preventable. Through the Family and Community Support Services Social Sustainability Framework (FCSS-SSF) stakeholders can work together to inform public policy and support research based prevention programs. The authors highlight two specific prevention programs funded by the FCSS-SSF where culture is a common ground among members. The programs Little Dancing Buffalo and Native Network (each is explained in more depth within the article) both embrace Aboriginal culture, traditions, and teachings that are important for eliminating the alienation that First Peoples experience within the city. These programs help to strengthen relationships between Aboriginal children and adults who feel left out by mainstream society. Programs such as these offer celebratory activities (e.g. drumming, singing, pow wows, potlatches, etc.) as a way of revitalizing the spirit and bring divided communities together. The authors also note that these two specific programs help First Peoples transition to urban life, provide support, gives a sense of belonging and produces communities that appreciate Aboriginal traditions.

The second last article by Cindy Blackstock entitled, Wanted: Moral Courage in Canadian Child Welfare (pp. 35-46) examines moral courage in the face of neglect within the child welfare field as to the needs of Aboriginal families and the continued underfunding of child welfare services in First Nations communities by the Federal government. Blackstock notes that child welfare has neglected the inequalities facing First Peoples children and their families for too long despite strong evidence and solutions outlined in studies such as the Canadian Incidence Study of Abuse and Neglect (CIS). The CIS highlights factors like poverty, poor housing and substance misuse which have been identified as contributing to the overrepresentation of First Nations children and youth in the child welfare systems across Canada. Social workers rarely receive training to alleviate these issues for families. Coupled with this neglect is the inequitable funding by the 


\section{Editorial}

Federal government to adequately deal with the real problems facing Aboriginal families involved with child welfare. Blackstock demonstrates through her own experiences how this neglect and underfunding can be ameliorated. Along with an examination and definition of what is moral courage is Blackstock draws upon her own experiences in working in child welfare to demonstrate where she has learned to exhibit moral courage - that is, doing what is right by families despite that was expected of her as a subordinate and regardless of the consequence to her own wellbeing. As the literature revealed no studies on moral courage Blackstock instead chooses to reflect on an earlier moment in her career as a social worker where she drew upon moral courage to deliberately act insubordinate in order to do the right thing for a family she felt faced an unnecessary child protection investigation. Since that time she has exhibited moral courage in facing the Federal government by filing a joint Human Rights Complaint with the Assembly of First Nations against the Federal government in response to discriminatory funding to First Nations child welfare agencies. Blackstock share examples of other individuals in the past who have exhibited moral courage (i.e. Dr. Peter Henderson Bryce and Judge Kimmelman) as is the notable mention of children and youth who
Blackstock admires for their moral courage to stand up in support of other Aboriginal children and youth (e.g. Jordan River Anderson, Shannon Koostatchin). Blackstock concludes that the consequences of failing to center moral courage in social work discussions and practice as well as among community members involved with the safety and wellbeing of children need to be explored. The systemic nature of the social work professions' failure to do better when they ought to have known and can do better, demands nothing less.

The last article in this volume reviews a book on the narratives emerging from interracial adoptions that are rarely considered in child welfare. The differential treatment of Black children adopted by non-Black families versus the experience of Aboriginal children adopted by non-Aboriginal families resulted in different experiences and reactions. Adoptions involving Black children were characterized as "saving" them while adoptions involving Aboriginal children are equated with colonialism, cultural assimilation and genocide. This book no doubt will be an important addition to the libraries of those interested in adoption issues regarding Aboriginal peoples. 